\title{
Budidaya Selada pada Vertikultur Hidroponik Sistem Karpet
}

\section{Lettuce Cultivation on Hydroponic Verticulture of Carpet System}

\author{
Hanggoro Sabdo Pamungkas ${ }^{1)}$, Retno Bandriyati Arni Putri ${ }^{2}$, Endang Setia Muliawati ${ }^{2}$
}

\begin{abstract}
The limitation of land area that for fulfillment of food savety needs to be resolved immediately. One of the things that can be done, is the use technology of verticulture system without soil media. Pouch system use the carpet is one verticulture system that can be applied. Basically, carpet is capable of holding water and has a high capillarity, so it can be used as a media pit as conductor of nutrients to the substrat medium. This study aimed to evaluate the hydroponic verticulture of carpet system on lettuce cultivation. This study was conducted in August 2013 to October 2013 at the Greenhouse B, Faculty of Agriculture, University of Sebelas Maret Surakarta. The treatments was arranged based on the completely randomized design (CRD) used factorial with 2 factor consists of 4 level and one control. Each treatment was repeated 3 times. Based on the efficiency use of nutrients and electric cost, the result showed that vertical cross pattern and 15 minutes fertigation treatments gave best results.
\end{abstract}

Keywords : hydroponic, carpet system, lettuce

\section{PENDAHULUAN}

Kebutuhan sayuran semakin meningkat khususnya di daerah perkotaan. Upaya dalam mendukung program ketahanan pangan dan gizi dengan budidaya sayuran di sekitar pekarangan terbentur dengan lahan pekarangan yang semakin sempit, terutama di perkotaan. Salah satu alternatif untuk menyiasati terbatasnya lahan budidaya adalah dengan menggunakan teknologi hidroponik. Menurut Lonardy (2006), penggunaan sistem hidroponik tidak mengenal musim dan tidak memerlukan lahan yang luas dibandingkan dengan kultur tanah untuk menghasilkan produktivitas yang sama. Teknologi hidroponik mengharuskan kemampuan khusus penggunanya dalam pengoperasian dan keuntungan menggunakan sistem ini memungkinkan kontrol terhadap tanaman lebih baik. Menurut Savvas et al. (2006), pengetahuan khusus untuk mencegah gangguan gizi dan mengoptimalkan pertumbuhan tanaman dalam sistem hidroponik tertutup sangat diperlukan. Menurut Saito et al. (2013) penggunaan teknologi hidroponik membuat lingkungan sekitar tanaman lebih dapat dikontrol.

Teknik hidroponik yang memungkinkan dimodifikasi adalah dengan sistem vertikultur. Menurut Maya (2012), sistem pertanian vertikultur adalah sistem budidaya pertanian yang dilakukan secara vertikal atau bertingkat. Kelebihan dari sistem pertanian vertikultur adalah efisiensi penggunaan lahan karena yang ditanam jumlahnya lebih banyak dibandingkan pemakaian pupuk dan pestisida, kemungkinan tumbuhnya rumput dan gulma lebih

\footnotetext{
${ }^{1)}$ Undergraduate Student of Study Program of Agrotechnology, Faculty of Agriculture University of Sebelas Maret (UNS) in Surakarta.

${ }^{2)}$ Lecturer of Study Program of Agrotechnology, Faculty of Agriculture University of Sebelas Maret (UNS) in Surakarta.
}

Contact Author: endangsetia_agr@ymail.com kecil, dapat dipindahkan dengan mudah karena tanaman diletakkan dalam wadah tertentu, dan mempermudah monitoring/pemeliharaan tanaman.

Salah satu produk hortikultura yang memiliki nilai ekonomis tinggi adalah selada. Selada (Lactuca sativa L.) adalah tanaman sayuran daun yang banyak diproduksi dan dikonsumsi di dunia (Li et al. 2010), dan merupakan salah satu sayuran hidroponik yang paling banyak ditanam. Menurut Becker et al. (2013) pada musim dingin di Eropa Tengah, selada banyak ditanam di dalam green house. Selada mengandung klorofil dan vitamin $\mathrm{K}$, vitamin $\mathrm{A}$ dan B6, asam folat likopen, dan zeaxanthin. Selada mengandung alkaloid yang bertanggung jawab untuk efek terapeutik. Selama ini selada dikonsumsi sebagai bahan Ialapan. Salah satu macam selada adalah selada merah. Selada merah (Lactuca sativa L.) merupakan tanaman yang semakin penting dan sumber makanan polifenol yang baik karena mengandung beberapa asam fenolik (turunan asam caffeic) dan flavonoid (quercetin, luteolin dan cyanidin) glikosida (Llorach et al. 2008) Selada sebagai salah satu pelengkap dalam masakan dinilai dapat digunakan untuk pemenuhan pangan dan gizi masyarakat. Melihat dari semakin sempitnya lahan dan meningkatnya kebutuhan pangan dan gizi masyarakat perlu dilakukan penelitian kajian sistem vertikultur hidroponik sistem karpet pada budidaya selada.

\section{METODE PENELITIAN}

Penelitian ini dilaksanakan pada bulan Agustus 2013 sampai Oktober 2013 di Rumah Kaca B Fakultas Pertanian Universitas Sebelas Maret Surakarta. Analisis Laboratorium di Laboratorium Ekologi Manajemen Produksi Tanaman Fakultas Pertanian Universitas Sebelas Maret Surakarta. Bahan penelitian yang digunakan adalah benih selada merah red rapid, arang sekam, pakis cacah, kompos, air, garam teknis meliputi Kalium nitrat $\left(\mathrm{KNO}_{3}\right)$, Kalsium nitrat $\left(\mathrm{CaNO}_{3}\right)$, monokalium fosfat $\left(\mathrm{KH}_{2} \mathrm{PO}_{4}\right)$, magnesium sulfat $\left(\mathrm{MgSO}_{4}\right)$, Fe EDTA, 
mangan sulfat $\left(\mathrm{MnSO}_{4}\right)$, Tembaga sulfat $\left(\mathrm{CuSO}_{4}\right)$, seng sulfat $\left(\mathrm{ZnSO}_{4}\right)$, asam borat $\left(\mathrm{H}_{3} \mathrm{BO}_{3}\right)$, amonium hepta molibdat $\left.\left(\mathrm{NH}_{4}\right)_{6} \mathrm{MO}_{7} \mathrm{O}_{24} \cdot 4 \mathrm{H}_{2} \mathrm{O}\right)$. Alat penelitian yang digunakan adalah karpet, besi penyangga, bambu penegak, alat-alat untuk penanaman, timer, pompa submersible dengan spesifikasi : Power 20 watt, Qmax 2000 liter/ jam, Hmax 2 meter, penggaris, timbangan, termometer, dan oven.

Penelitian ini menggunakan Rancangan Acak Lengkap dengan 2 faktor perlakuan yang disusun secara faktorial yaitu pola tanam pada karpet (pola sejajar dan pola bersilang) dan sistem fertigasi (fertigasi berselang 15 dan 30 menit) sehingga didapatkan perlakuan yaitu :

1. Pola vertikal sejajar + fertigasi berselang 15 menit

2. Pola vertikal sejajar + fertigasi berselang 30 menit

3. Pola vertikal bersilang + fertigasi berselang 15 menit

4. Pola vertikal bersilang + fertigasi berselang 30 menit

5. Kontrol (Ditanam di polibag + penyiraman manual pada pagi dan sore).

Tiap perlakuan dan kontrol diulang 3 kali sehingga didapat 15 perlakuan. Tahap-tahap pelaksanaan penelitian meliputi penyiapan alat, pembibitan, penyiapan media, penanaman, pembuatan larutan nutrisi, pengaturan fertigasi, penyulaman, pemeliharaan, dan pemanenan. Pengamatan penelitian meliputi tinggi tanaman, jumlah daun, panjang batang, luas daun, berat segar tanaman, berat kering tanaman, berat segar akar, dan berat kering akar. Data hasil penelitian dianalisis dengan menggunakan analisis ragam. Untuk mengetahui perbedaan respon antar perlakuan digunakan uji pembanding rerata metode DMRT (Duncan Multiple Range Test) taraf 5\%.

\section{HASIL DAN PEMBAHASAN}

Selada merah memiliki warna daun yang kemerahan. Selada merah tumbuh optimal di dataran tinggi tetapi saat ini telah banyak dikembangkan varietas yang tahan pada suhu panas. Umur panen selada merah sekitar 35 hari setelah pindah tanam. Sistem pemberian nutrisi menggunakan fertigasi. Fertigasi memungkinkan pemberian nutrisi ke tanaman dengan jumlah yang tepat dan waktu yang sesuai pada tahap tertentu dari pertumbuhan tanaman (Salih et al. 2012). Fertigasi yang diberikan menggunakan sistem tersirkular secara berselang. Fertigasi berselang merupakan fertigasi yang diberikan secara bertahap sesuai waktu yang diinginkan. Penyiraman dilakukan secara otomatis dengan menggunakan pompa air serta timer sebagai pengatur waktu penyiraman. Timer diatur agar penyiraman dilakukan jam 07.00, 08.00, 09.00 kemudian 14.00, 15.00, 16.00. Pada fertigasi berselang 15 menit didapatkan pengaturan penyiraman 15 menit nutrisi mengalir kemudian 45 menit mati, sedangkan pada fertigasi berselang 30 menit didapatkan pengaturan penyiraman 30 menit nutrisi mengalir kemudian 30 menit mati.

Kecepatan pertumbuhan tinggi tanaman selada antar tiap perlakuan pola dan fertigasi berselang hampir sama.

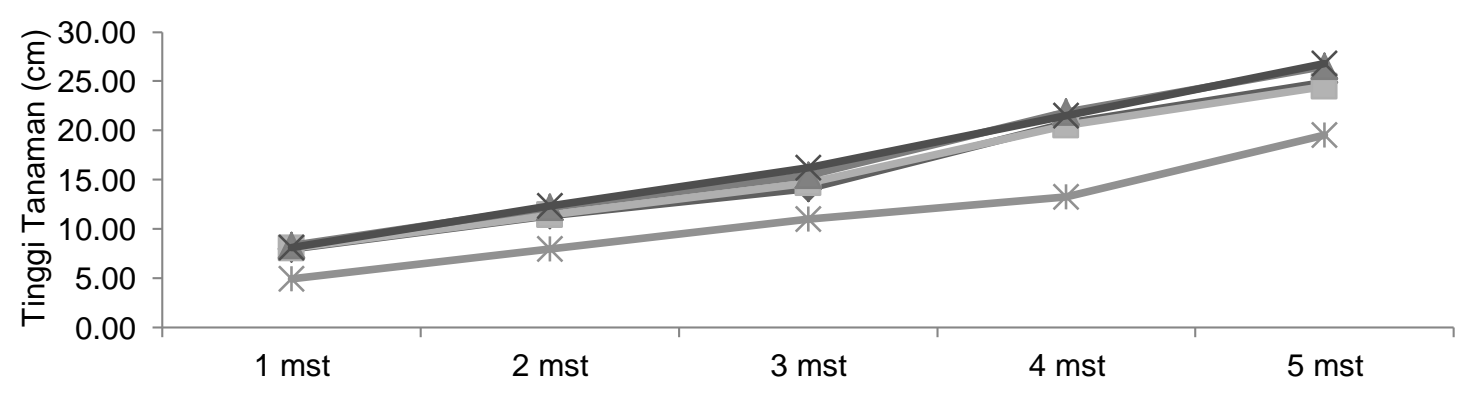

Waktu

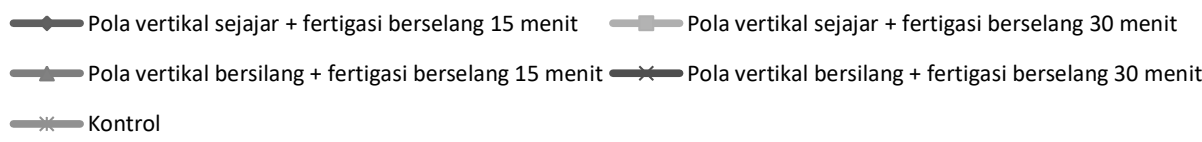

\section{Gambar 1. Pola pertumbuhan tinggi selada merah}

Jika dibandingkan kontrol yang ditanam di polibag dengan penyiraman manual pada pagi dan sore, tiap perlakuan memiliki kecepatan pertumbuhan tinggi tanaman lebih baik. Kecepatan pertumbuhan pada tiap perlakuan di awal 1 minggu setelah tanam (MST) sudah mulai meningkat. Kecepatan pertumbuhan tertinggi keseluruhan perlakuan terdapat pada 3 MST menuju 4 MST. Pada kontrol kecepatan pertumbuhan tinggi tanaman dapat dikatakan rendah pada umur tanaman 1-4 MST, dibanding tiap perlakuan sedangkan pada minggu ke-5 pertumbuhan kontrol naik lebih cepat dibanding minggu sebelumnya.

Berdasarkan Tabel 1 menyatakan respon pertumbuhan tinggi selada merah umur 5 MST pada semua perlakuan pola dan fertigasi berselang lebih tinggi dan berbeda nyata dengan kontrol selada merah yang ditanam di polibag, tetapi pada antara tiap perlakuan pola tanam dan fertigasi berselang 
tidak berbeda nyata. Tinggi tanaman selada merah tertinggi terdapat pada perlakuan pola bersilang dan fertigasi berselang 30 menit yaitu $26,8 \mathrm{~cm}$. Tinggi tanaman selada merah terendah terdapat pada kontrol selada merah yang ditanam di polibag yaitu $19,5 \mathrm{~cm}$. Pola bersilang menunjukkan hasil terbaik. Hal tersebut dimungkinkan karena intensitas persaingan untuk mendapatkan hara dan cahaya yang lebih kecil dibandingkan dengan yang pola sejajar. Pada pola bersilang pola tanam yang menyilang antar baris membuat tanaman tidak saling menutupi serta kesempatan tanaman untuk mendapatkan nutrisi yang memiliki kualitas optimal lebih baik. Pada pola sejajar jarak antar tanaman lebih rapat sehingga persaingan untuk mendapatkan hara dan cahaya lebih tinggi. Pada fertigasi berselang 15 dan 30 menit memberikan hasil yang tidak berbeda nyata. Hal tersebut disebabkan karena fertigasi berselang 15 menit nutrisi untuk tanaman sudah tercukupi. Fertigasi merupakan hal yang penting bagi pertumbuhan tanaman. Menurut Yaghi et al. (2013), bahwa fertigasi merupakan faktor pembatas penting dari hasil panen, karena terkait dengan banyak faktor lingkungan tanaman, yang mempengaruhi pertumbuhan dan perkembangan tanaman.

Tabel 1 Komponen pertumbuhan dan hasil selada merah

\begin{tabular}{|c|c|c|c|c|c|c|c|c|}
\hline Perlakuan & $\begin{array}{c}\text { Tinggi } \\
\text { Tanaman }\end{array}$ & $\begin{array}{l}\text { Jumlah } \\
\text { Daun }\end{array}$ & $\begin{array}{c}\text { Panjang } \\
\text { Batang }\end{array}$ & $\begin{array}{l}\text { Luas } \\
\text { Daun }\end{array}$ & $\begin{array}{l}\text { Berat } \\
\text { Segar } \\
\text { (gr) }\end{array}$ & $\begin{array}{l}\text { Berat } \\
\text { Kering } \\
\text { (gr) }\end{array}$ & $\begin{array}{c}\text { Berat } \\
\text { Segar } \\
\text { Akar } \\
(\mathrm{mg})\end{array}$ & $\begin{array}{c}\text { Berat } \\
\text { Kering } \\
\text { Akar } \\
(\mathrm{mg})\end{array}$ \\
\hline $\begin{array}{l}\text { Pola vertikal sejajar } \\
\text { + fertigasi } \\
\text { berselang } 15 \text { menit }\end{array}$ & $24,9^{b}$ & $8,3^{b}$ & $13,5^{b}$ & $56,9^{a}$ & $16,41^{a}$ & $1,19^{\mathrm{ab}}$ & $787^{\mathrm{a}}$ & $85,3^{\mathrm{a}}$ \\
\hline $\begin{array}{l}\text { Pola vertikal sejajar } \\
\text { + fertigasi } \\
\text { berselang } 30 \text { menit }\end{array}$ & $24,5^{\mathrm{b}}$ & $8,1^{\mathrm{b}}$ & $13,2^{b}$ & $57,4^{a}$ & $14,38^{\mathrm{a}}$ & $1,19^{\mathrm{ab}}$ & $807^{a}$ & $90,7^{\mathrm{a}}$ \\
\hline $\begin{array}{l}\text { Pola vertikal } \\
\text { bersilang + fertigasi } \\
\text { berselang } 15 \text { menit }\end{array}$ & $26,5^{\mathrm{b}}$ & $8,3^{\mathrm{b}}$ & $14,1^{\mathrm{D}}$ & $67,9^{a}$ & $17,94^{\mathrm{a}}$ & $1,52^{b}$ & $818^{a}$ & $89,3^{a}$ \\
\hline $\begin{array}{l}\text { Pola vertikal } \\
\text { bersilang + fertigasi } \\
\text { berselang } 30 \text { menit }\end{array}$ & $26,8^{b}$ & $8,7^{\mathrm{b}}$ & $14,6^{b}$ & $68,7^{\mathrm{a}}$ & $20,47^{a}$ & $1,32^{b}$ & $1007^{a}$ & $125,3^{a}$ \\
\hline Kontrol & $19,5^{a}$ & $7,0^{\mathrm{a}}$ & $3,6^{a}$ & $57,9^{a}$ & $11,67^{\mathrm{a}}$ & $0,72^{\mathrm{a}}$ & $767^{a}$ & $76,7^{\mathrm{a}}$ \\
\hline
\end{tabular}

Keterangan: Angka yang diikuti huruf yang sama tidak berbeda nyata pada uji DMRT taraf $5 \%$.

Berdasarkan Tabel 1 menunjukkan bahwa respon jumlah daun selada merah umur 5 MST pada semua perlakuan pola dan fertigasi berselang pada sistem vertikultur menunjukkan hasil lebih tinggi dan berbeda nyata dibandingkan dengan kontrol selada merah yang ditanam di polibag, sedangkan pada semua perlakuan menunjukkan hasil yang tidak berbeda nyata. Semua perlakuan pola dengan fertigasi berselang menunjukkan hasil yang sama tinggi yaitu rata-rata jumlah daun sekitar 8 buah. Pada kontrol, jumlah daun yang muncul menunjukkan 7 buah, yang merupakan hasil terendah. Perlakuan fertigasi berselang 15 dan 30 menit menunjukkan hasil yang tidak berbeda. Hal ini dimungkinkan karena fertigasi berselang 15 menit sudah mampu menyuplai hara. Kelebihan dari nutrisi dalam hal ini akan kembali ke bak penampungan. Pemberian nutrisi dengan frekuensi dan durasi waktu yang memadai akan menjamin ketersediaan nutrisi di permukaan akar dan sekitarnya tercukupi, selama irigasi dan jelang redistribusi irigasi selanjutnya (Silber et al. 2005). Menurut lqbal (2006), cara fertigasi dengan mesin pompa efektif meningkatkan pertumbuhan dan produksi tanaman serta efisien dalam penggunaan tenaga dan waktu. Sistem pemberian air secara sirkular, memberikan kecenderungan yang lebih baik dibandingkan sistem pemberian air secara menggenang karena larutan fertigasi terus menerus mengalir yang memungkinkan akar dapat selalu menyerap unsur hara setiap waktu (Wirosoedarmo et al. 2001).

Berdasarkan Tabel 1 menunjukkan bahwa respon panjang batang selada merah umur 5 MST terhadap cara tanam sistem vertikultur dengan perlakuan pola dan fertigasi berselang lebih tinggi dan berbeda nyata dengan kontrol selada merah yang ditanam di polibag. Respon yang tertinggi terdapat pada perlakuan pola bersilang dan fertigasi berselang 30 menit dengan nilai $14,6 \mathrm{~cm}$. Kontrol memberikan respon terendah dengan panjang batang rata-rata $3,6 \mathrm{~cm}$. Pada dasarnya selada daun merupakan tanaman yang memiliki batang pendek. Pada sistem vertikultur terjadi proses saling menaungi antar tanaman sehingga intensitas cahaya yang diterima kurang. Prawiranata et al. (1981) menyatakan bahwa bagian tanaman yang terkena cahaya mengandung auksin lebih rendah daripada bagian yang gelap/ternaungi. Auksin merangsang pemanjangan sel dan akibatnya juga pemanjangan batang.

Berdasarkan Tabel 1, menyatakan bahwa perlakuan pola dan fertigasi berselang pada sistem vertikultur tidak menunjukkan pengaruh yang nyata terhadap respon luas daun pada selada merah umur 5 MST. Perlakuan pola sejajar dan fertigasi berselang 
15 menit menunjukkan hasil terendah dengan luas daun $56,9 \mathrm{~cm}^{2}$. Pada pola bersilang dan fertigasi berselang 30 menit menunjukkan hasil tertinggi dengan luas daun $68,7 \mathrm{~cm}^{2}$. Pada kontrol selada merah yang ditanam di polibag menunjukkan hasil luas daun mencapai $57,9 \mathrm{~cm}^{2}$. Pola sejajar dan bersilang tidak terlalu berbeda nyata hasilnya. Hal tersebut dimungkinkan penyerapan nutrisi yang sudah mencukupi. Menurut Hansen et al. (1992), pertumbuhan tanaman tidak boleh terhambat oleh kurangnya ketersediaan air. Jika air irigasi tidak ada saat tanaman benar-benar membutuhkan air, maka akan menghambat pertumbuhan, oleh karena itu interval waktu pemberian nutrisi perlu diperhatikan. Pengaturan fertigasi berselang yang optimal sangat penting untuk efisiensi air, nutrisi, serta meningkatkan produktivitas dan kualitas tanaman yang ditanam di rumah kaca (Noh et al. 2012).

Berdasarkan hasil Tabel 1, menyatakan bahwa perlakuan pola dan fertigasi berselang tidak memberikan hasil yang berbeda nyata terhadap respon berat segar selada merah umur 5 MST. Perlakuan pola bersilang dan fertigasi berselang 30 menit memberikan hasil tertinggi dengan berat segar 20,47 gram. Kontrol memberikan respon berat segar 11,67 gram yang merupakan hasil terkecil. Dilihat dari hasil yang tidak berbeda nyata, perlakuan pola bersilang dan fertigasi berselang 15 menit memberikan hasil paling baik. Hal tersebut dikarenakan fertigasi berselang 15 menit lebih efisien dalam pemberian nutrisi dan lebih hemat untuk penggunaan listrik. Pola bersilang memberikan hasil tertinggi dibandingkan dengan pola sejajar. Hal tersebut dimungkinkan persaingan antar tanaman yang lebih kecil dan kondisi iklim mikro pada pola bersilang lebih ideal bagi tumbuh tanaman selada. Menurut Mawazin dan Suhaendi (2008), semakin rapat jarak tanam semakin banyak populasi tanaman per satuan luas, sehingga persaingan hara antar tanaman semakin ketat. Akibatnya pertumbuhan tanaman akan terganggu dan produksi per tanaman akan menurun. Semakin rapat jarak akan berpengaruh juga terhadap kelembaban pada media. Selain itu ketersediaan dan kualitas hara yang optimal memberikan dampak positif terhadap hasil tanaman. Ketersediaan hara yang rendah menghambat fisiologi tumbuhan yang akan berdampak pada hasil tanaman (Junita et al. 2002).

Berdasarkan data Tabel 1 menyatakan bahwa pola bersilang dan fertigasi berselang 15 menit lebih tinggi dan berbeda dibandingkan kontrol pada respon berat kering selada merah umur 5 MST. Pada tiap perlakuan pola dan fertigasi berselang tidak menunjukkan hasil berbeda. Hasil tertinggi terdapat pada pola bersilang dan fertigasi berselang 15 menit dengan rata-rata berat kering brangkasan $1,52 \mathrm{~g}$. Hasil terendah pada kontrol dengan rata-rata berat kering brangkasan $0,72 \mathrm{~g}$. Pada pola tanam bersilang berat kering brangkasan memiliki hasil terbaik dibandingkan dengan pola sejajar. Hal tersebut dimungkinkan karena penerimaan cahaya pada pola bersilang lebih baik. Pola tanam bersilang memberikan kesempatan untuk tanaman menerima kualitas nutrisi yang lebih baik. Pola bersilang memiliki pola yang mana letak lubang pada baris pertama dengan baris kedua tidak pada satu garis lurus, sehingga baris kedua memiliki kesempatan untuk menerima nutrisi yang sama baik dengan baris pertama. Pada pola tanam sejajar, tanaman lebih saling menaungi karena kerapatan tanaman yang lebih dibandingkan pola bersilang. Bila dibandingkan dengan kontrol, baik pola bersilang dan pola sejajar memiliki berat kering brangkasan yang lebih besar. Hal tersebut diduga karena adanya sistem pola fertigasi otomatis yang menyebabkan nutrisi lebih tersirkular, sehingga kandungan $\mathrm{O}_{2}$ terlarut pada nutrisi yang lebih banyak. Hal tersebut menjadikan penyerapan nutrisi yang lebih baik. Menurut Drew dan Stolzy (1991), gangguan akar sebagai akibat kekurangan oksigen (deoksigenasi) adalah pertumbuhan dan perkembangan tanaman yang tidak sempurna serta menurunnya hasil panen.

Berdasarkan Tabel 1 menyatakan bahwa respon berat segar akar selada merah umur 5 MST yang dihasilkan perlakuan pola dan fertigasi berselang memperlihatkan hasil yang tidak berbeda nyata. Perlakuan pola bersilang dan fertigasi berselang 30 menit menunjukkan hasil tertinggi dengan berat ratarata $1007 \mathrm{mg}$. Hasil terkecil terdapat pada kontrol yang ditanam di polibag dengan rata-rata berat 767 mg. Menurut Mechram (2006), untuk mendapatkan pertumbuhan yang baik, tanaman harus mempunyai akar dan sistem perakaran yang cukup luas untuk dapat memperoleh nutrisi dan air sesuai dengan kebutuhan tanaman. Pada fertigasi berselang 30 menit, aliran nutrisi lebih banyak sehingga ketersedian nutrisi lebih banyak. Hal tersebut akan mempengaruhi sistem perakaran yang menjadikan sistem perakaran pada fertigasi berselang 30 menit lebih luas. Fertigasi yang berselang secara otomatis membuat suplai oksigen pada akar tanaman lebih baik. Menurut Abuarab et al. (2013), akar tanaman membutuhkan pasokan oksigen yang baik dalam rangka untuk memenuhi kebutuhan air dan nutrisi untuk pertumbuhan.

Berdasarkan Tabel 1 menyatakan bahwa perlakuan pola dan fertigasi berselang tidak berpengaruh nyata pada berat kering akar. Nilai tertinggi terdapat pada pola bersilang dan fertigasi berselang 30 menit yaitu $125,3 \mathrm{mg}$. Nilai terendah pada kontrol yaitu $76,7 \mathrm{mg}$. Pola bersilang memberikan hasil terbaik, hal ini dimungkinkan penyerapan nutrisi yang lebih baik. Pola bersilang memberikan kemampuan tanaman untuk menyerap nutrisi lebih optimal dibanding dengan pola sejajar. Hal ini dimungkinkan lebih baiknya kualitas nutrisi yang didapat karena persaingan hara antar tanaman lebih sedikit dan alur aliran nutrisi yang lebih baik.

\section{KESIMPULAN DAN SARAN}

\section{Kesimpulan}


Berdasarkan hasil penelitian yang dilakukan dapat disimpulkan bahwa dilihat dari hasil yang tidak berbeda nyata antara pola bersilang dan fertigasi berselang 30 menit dengan pola bersilang dan fertigasi berselang 15 menit, berdasarkan efisiensi nutrisi dan energi listrik maka pola bersilang dan fertigasi berselang 15 menit memberikan hasil terbaik untuk pertumbuhan dan hasil selada merah.

\section{Saran}

Perlu dilakukan penelitian lanjutan untuk mengkaji lebih dalam. Perlu dikembangkan lanjut dengan menguji cara fertigasi lainnya, misal melalui drip irigasi pada tiap lubang. Selain itu bisa lebih dikaji lagi masalah media campurannya.

\section{DAFTAR PUSTAKA}

Abuarab M, Mostafa E, Ibrahim M. 2013. Effect of air injection under subsurface drip irrigation on yield and water use efficiency of corn in a sandy clay loam soil. J Adv Res 4(6): 493-499.

Becker C, Klaeringa HP, Krohb LW, Krumbein A. 2013. Cool-cultivated red leaf lettuce accumulates cyaniding - 3-O - (6"-O-malonyl) - glucoside and caffeoylmalic acid. Food Chemistry 146(9): 404411

Hansen VEO, Israelsen W, Stringham G, Tachyan EP. 1992. Dasar-dasar dan praktek irigasi. Jakarta (ID): Erlangga.

Iqbal M. 2006. Penggunaan pupuk majemuk sebagai sumber hara pada budidaya bayam secara hidroponik dengan tiga cara fertigasi. Skripsi. Fakultas Pertanian, IPB.

Junita, Fitra, Muhartini S, Kastono D. 2002. Pengaruh frekuensi penyiraman dan takaran pupuk kandang terhadap pertumbuhan dan hasil pakchoi. J IImu Pert IX(1).

Li Z, Zhao X, Sandhu AK, Gu L. 2010. Effects of exogenous abscisicacid on yield, antioxidant capacities, and phytochemical contents of greenhouse grown lettuces. J Agric Food Chem 58: 6503-6509.

Llorach R, Martínez-Sánchez A, Tomás-Barberán FA, Gil MI, Ferreres F. 2008. Characterisation of polyphenols and antioxidant properties of five lettuce varieties and escarole. Food Chemistry, 108(3): 1028-1038.

Lonardy MV. 2006. Respons tanaman tomat (Lycopersicon esculentum mill.) terhadap suplai senyawa nitrogen dari sumber berbeda pada sistem hidroponik. Skripsi. Universitas Tadulako.

Mawazin, Suhaendi H. 2008. Pengaruh jarak tanam terhadap pertumbuhan diameter shorea parvifolia dyer. J Penel Hutan dan Kons Alam 5(4): 381-388.

Maya R. 2012. Budidaya tanaman sayuran secara vertikultur sederhana. Bangka Belitung. Balai Pengkajian Teknologi Pertanian Kepulauan Bangka Belitung.

Mechram S. 2006. Aplikasi teknik irigasi tetes komposisi media tanam pada selada (lactuca sativa). J Tek Pert 7(1): 27-36.

Noh EH, Son JE, Shin JH, Ta H. 2012. Transpiration, growth, and water use efficiency of paprika plants (Capsicum annuum L.) as affected by irrigation frequency. Hort Environ Biotechnol 53(2): 129-134.

Prawiranata W, Haran S, Tjondronegoro P. 1981. Dasar-dasar fiologi tumbuhan. Jilid II. Bogor (ID): Institut Pertanian Bogor.

Saito K, Furue K, Kametani H, Ikeda M. 2013. Roots of hydroponically grown tea (Camellia sinensis) plants as a source of a unique amino acid, theanine. American J Exp Agric 4(2): 125-129.

Salih JEM, Adom AH, Shaakaf AYM. 2012. Solar powered automated fertigation control system for Cucumis melo L. cultivation in green house. APCBEE Procedia 4: 79-87.

Savvas D, Passam HC, Olympios C, Nasi E, Moustaka E, Mantzos N, Barouchas P. 2006. Effects of ammonium nitrogen on lettuce grown on pumice in a closed hydroponic system. Hort Sci 41(7): 1667-1673.

Silber A, Bruner M, Kenig E, Reshef G, Zohar H, Posalski I, Yehezkel H, Shmuel D, Cohen S, Dinar M, Matan E, Dinkin I, Cohen Y, Karni L, Aloni B, Assouline S. 2005. High fertigation frequency and phosphorus level: effects on summer-grown bell pepper growth and blossom-end rot incidence. $J$ Plant Soil 270: 135-146.

Wirosoedarmo J, Rahadi B, Ermayanti D. 2001. Pengaruh sistem pemberian air dan ketebalan spon terendam terhadap pertumbuhan tanaman sawi (Brassica juncea) dengan metode aqua culture. J Tek Pert 2(2): 52-57.

Yaghi T, Arslan A, Naoum F. 2013. Cucumber (Cucumis sativus, L.) water use efficiency (WUE) under plastic mulch and drip irrigation. Agric Water Man 128: 149-157. 